\title{
Renal Shell injuries with Retaining renal shell fragments due to improvised explosive devices. Acute conservative approach and long term follow-up
}

Murat Zor (D murat804@yahoo.com)

Gülhane EAH: Ankara Gulhane Egitim ve Arastirma Hastanesi https://orcid.org/0000-0003-2597-5026

Bahadir Topuz

GEAH

Engin Kaya

Gülhane EAH: Ankara Gulhane Egitim ve Arastirma Hastanesi

Sercan Yilmaz

Gülhane Training and Research Hospital: Ankara Gulhane Egitim ve Arastirma Hastanesi

\section{Sinan Akay}

Gülhane EAH: Ankara Gulhane Egitim ve Arastirma Hastanesi

Selahattin Bedir

Gülhane EAH: Ankara Gulhane Egitim ve Arastirma Hastanesi

\section{Research}

Keywords: renal shell fragments, shrapnel injuries, non-operative management, renal trauma

Posted Date: January 13th, 2021

DOI: https://doi.org/10.21203/rs.3.rs-142874/v1

License: @ (i) This work is licensed under a Creative Commons Attribution 4.0 International License. Read Full License 


\section{Abstract}

Introduction: Among penetrating injuries, renal shrapnel injuries consist of a rarity of renal gunshot injuries. Due to the paucity of cases reported in the literature, there is no consensus regarding the management of renal shrapnel injuries and retaining renal shell fragments. In this study we aimed to report our non-operative management experience of renal shrapnel injuries who had also retaining renal shell fragments.

Material and Methods: We retrospectively evaluated the medical records of renal shrapnel injuries that had also retaining renal shell fragments. All hemodynamically stable patients managed non-operatively and included to the study. The medical records of age, renal injury grade according to AAST, presenting pulse, systolic blood pressure, transfusion requirement, complications and need for adjuvant procedures, non-operative management success and mortality was reviewed. Complication rates due to retaining renal shell fragments were assessed by interviewing via telephone at the end of the first year of injury. The patients asked for plumbism symptoms and any surgical intervention for these foreign bodies.

Results: A total of 8 patients with retaining renal shell fragments due to renal shrapnel injuries were included to the study. Mean patient age was 27,8 years. Mean follow-up period was $38.7 \pm 15.1$ months. All patients were male. AAST renal injury scores were grade 1 one, grade 2 two, grade 3 four, grade 4 one patient. All patients were successfully managed non-operatively and discharged on the 7th day without any complication. No symptoms of plumbism and surgery necessity secondary to retaining renal shell fragments were seen in at least one year follow-up.

Conclusion: Our study demonstrates that non-operative management of renal shrapnel injuries with retaining renal shell fragments lead low complication rates and high chance of renal preservation. However, we must keep in mind that this kind of management is safe in experienced trauma centers that have experienced staff.

\section{Introduction}

Blast- and gunshot-related injuries are common in countries in which war activities are prevalent. But renal wounds consists of a minority of these injuries with being more complex ones. Such injuries are sometimes associated with a retained shell fragments or bullets. Many of them often undergo emergency operation rooms. Nevertheless, the management of renal trauma has been shifted from immediate surgical exploration and nephrectomy to renoraphies and finally to non-operative management strategies especially in hemodynamically stable patients (1). Even for renal gunshot or blast injuries some authors advocate non-operative management $(2,-4)$. Renal shell fragment injuries are caused by traveling shell fragments secondary to the explosion of an improvised explosive devices (IED) or rocket propelled grenades (RPG). They consist of a rarity of all renal blast- and gunshot-related injuries. The injury is mostly develops by explosives that are performed by terrorist attacks. The shell fragments mostly affect musculoskeletal system and soft tissues and very rarely kidney, mostly causing local damage and infection $(5,6)$. Due to the paucity of cases reported in the English literature, there is no consensus regarding the management of renal traumas with retaining renal shell fragments caused by IEDs.

In this study, with the growing experience and popularity of non-operative management of renal injuries in combination with renal salvage benefits, we aimed to report our non-operative management experience of 8 cases of renal shell fragment caused injuries who had also retaining shell fragments in renal parenchyma.

\section{Material And Methods}

After permission obtained by the Institutional Review Board of our University, a retrospective study cohort was performed to evaluate the efficacy of nonoperative management of renal shell fragment wounds, and follow-up complication rates of these retaining renal shell fragments. The mechanism of injury was traveling shrapnel fragments secondary to the explosion of an IED of a terrorist attack. All patients with blast renal injuries were initially assessed and resuscitated according to Advanced Trauma Life Support Guidelines. In the case of intraperitoneal injury suspicion and hemodynamically instability, all patients immediately transferred to operating room and surgical exploration performed. The remaining stable patients who had shell fragment caused injuries underwent computed tomography (CT) imaging with delayed images for evaluating renal and ureteral injuries. American Association for the Surgery of Trauma (AAST) organ injury severity score for kidney was used for renal trauma grading (7). A final management program was then assessed and the patients with grade 5 injuries in combination with ureteral injuries underwent surgical exploration, while grade 1-4 injuries managed non-operatively. For this study we retrospectively evaluated the medical records of non-operatively managed renal shell fragments caused injuries that had also retaining renal shell fragments. AAST grade 5 injuries, patients that had ureteral injury and underwent surgical exploration, evidence of hollow viscus penetration/trauma, renal injuries without retaining renal shell fragments, and all other renal gunshot injuries were excluded from the study population.

For non-operative management all patients were transferred to a high care observation area for hemodynamic monitoring, and hemoglobin/hematocrit estimation for every 4 hours. A urethral catheter was inserted for monitoring fluid balance. All physical activities were restricted until hematuria resolved. When hemoglobin/hematocrit drop and hematuria was stopped, the patient transferred to inpatient ward. Repeat CT was performed on the $7^{\text {th }}$ day of trauma for reevaluation. If the injury regressed or resolved, both for hematoma or urinoma (if present), the patient was discharged. Strenuous physical activity was restricted for 4 weeks. Persistent or enlarging urinomas was managed either D-J stenting or percutaneous nephrostomy. Patients with decreasing hemoglobin or continuing macroscopic hematuria underwent renal angiography and selective embolization.

The medical records of age, grade of renal injury according to AAST, presenting pulse, systolic blood pressure, transfusion requirement, complications and need for adjuvant procedures, non-operative management success and mortality was reviewed. Complication rates due to retaining renal shell fragments were assessed by interviewing via telephone at the end of the first year of injury. The patients asked for plumbism symptoms and any surgical intervention for these foreign bodies. IBM SPSS statistics 24.0 software was used for statistical analysis. 


\section{Results}

A total of 8 patients with retaining renal shell fragments secondary to IEDs related renal juries were identified from our renal trauma database since 2016 . Mean patient age was 27,8 years (ranged between 24-44 years). Mean follow-up period was 38.7 \pm 15.1 months (ranged between $4-50$ months), with seven patient having nearly more than 3 years of follow-up. All patients were male. All hemodynamically instable patients underwent exploration, so none of the study cohort patients had recorded systolic blood pressure less than $90 \mathrm{mmHg}$, which was indicative for shock. Gross hematuria was present in three of eight patients (37.5\%). AAST renal injury scores were grade 1 one, grade 2 two, grade 3 four, grade 4 one patient. Control CT images of three patients in comparison with the venous phase and delayed images of the injury are shown in fig 1. As mentioned before neither grade 5 injuries nor accompanying adnominal injuries was included to the cohort. The patient and renal injury characteristics including age, AAST renal injury scores, site of injury, renal anatomic localization of the retaining shell fragments, admission systolic blood pressures and pulse rates, admission and 7th day serum urea/creatinine and hemoglobin/hematocrit levels, need for transfusion, and follow-up time for the entire eight patients were summarized in Table 1. All patients were successfully managed nonoperatively and discharged on the 7th day without any complication. At the end of the first year of trauma all patients asked for symptoms of plumbism and surgery necessity secondary to retaining renal shell fragments. Telephone interviews were used for this purpose and revealed no complication.

\section{Discussion}

In recent years, with the increasing incidence of global terrorist attacks, trap-bombs, improvised explosive devices (IEDs), and rock-et-propelled grenades (RPGs) related injuries have been a part of trauma centers of tertiary and military hospitals. Among these injuries, secondary blast injuries caused by traveling penetrating shell fragments are common source of explosion and combat related injuries $(8,9)$. But renal traumas due to these travelling shell fragments consist of a rarity. In some circumstances these shell fragments retain in the body and occasionally cause complications primarily depending on the anatomical location and the reaction with the surrounding tissue. In general, the shrapnel is thought to be left inert in the tissue, and can be managed conservatively. It can be removed in acute and subacute stage if there is need for debridement secondary to infection or later stage in cases of complications, such as local tissue complications (eg, abscess) or systemic toxicity (eg, plumbism) (5). Among all published English literature, there is only few case reports about renal shell fragments caused injuries $(10,11)$, and most of them are focusing on long term complications. When we searched PubMed we did not notice any paper focusing the management of renal shell fragments caused injuries secondary to explosives with retaining renal shell fragments.

Management of renal trauma leads excessive studies in the English literature. However, all penetrating injuries historically required exploration, improved imaging and interventional techniques, increased the role of non-operative management in some selected renal penetrating injuries (12, 13). In hemodynamically stable patients without any presence of intraabdominal injuries, non-operative management of penetrating renal injuries are now thought to be feasible $(12,14)$. With this increasing popularity of non-operative management of renal injuries over the last decades, in combination with the fact that the shell fragments are left inert in the tissue had encouraged us to manage these injuries non-operatively. So we conducted this retrospective study and reviewed our experience of such injuries. Our study's greatest value is being the largest and unique patient cohort of renal shell fragment wounds secondary to blast injuries with long term follow-up morbidity rates.

In our series seven patients had AAST grade 1-3 and one patient had AAST grade 4 renal injury. None had grade v injury. None required more than 4 units of blood transfusion except one with grade 4 injury. All had systolic blood pressure more than $90 \mathrm{mmHg}$, and pulse rate less than $120 \mathrm{bpm}$ at the hospital admission. In our patient cohort we were able to manage all patients without major surgical intervention, including nephrectomy, nephron sparing surgery and even renal embolization. When interpreting our results, we must keep in mind that our patient cohort was hemodynamically stable, and there was no sign of abdominal organ injury and peritonitis. In all patients preoperative imaging with contrast enhanced CT with delayed images revealed no pelvis or ureteral injury or major urine extravasation. But we must also keep in mind that our patient cohort is somehow different from all other studies with including only renal injuries caused by shell fragments. It is notable that none of our patients required adjuvant surgery, embolization or urinary diversion. We attributed the low adjuvant treatment necessity in our series to the low rate of AAST grade 4 renal injuries. In our patient cohort the entire population was eight patients and there was only one patient with AAST grade 4 renal trauma. Anyone can speculate that the increasing number of entire patient cohort in combination with increasing AAST renal injury grade may increase non-operative management failure and increase the necessity of adjuvant surgeries and procedures. But when we consider the rarity of the selected group among all renal injuries caused by explosives, our findings are very important for the literature.

Renal injuries caused by shell fragments are heavily contaminated with foreign bodies such as soil and clothing, with subsequent increased risk of infection (15). Despite increased risk of infection, empiric antibiotic use is still disputed due to increased risk of resistant infections. There is also discrepancy for the appropriate prophylactic antibiotic spectrum: a narrow or a broad-spectrum one (16). Historically gram-positive organisms like S. pyogenes and S. aureus are the major group of bacteria that are responsible for many infection types following penetrating traumas (17). In the literature there is no study focusing solely the antibiotic prophylaxis in either renal shrapnel injuries or renal gunshot injuries. In our series, we introduced prophylactic antibiotics because of the fact that all patients had retaining contaminated shell fragments that may lead infection. Tetanus prophylaxis was also done according to immunization status. No patient had neither renal abscess nor pyelonephritis during hospitalization or during follow-up period.

Although the fact that shell fragments are left inert in the tissue and there is no need for surgical removal in the late stage, they may be associated with several complications and must be removed in some circumstances (5). Late re-activation of retained metallic fragments has been reported in various organs (11) also including kidney. They can cause several pathological changes in adjacent organs or the organ itself. In a case Naeem et al reported renal colic and percutaneous removal of renal artillery shell fragment 17 years after primary exploding artillery shell injury (11). In another study, Jvaheri et al reported renal Failure in a Solitary Functioning Left Kidney secondary to a migrating $9 \mathrm{~mm}$ bullet ten years after injury (29). Retained shell fragments may also cause plumbism or exposure to depleted uranium due to release of chemical elements $(5,11,18)$. After mean 38.7 month of follow-up, we reached all patients in order to question the complication rates. We made a phone call and questioned if they have any sign of plumbism or need surgical intervention due to any complications of retaining shrapnel fragments. During 38.7 months of follow-up after primary trauma none had any systemic or local complications

Page 3/6 
secondary to retained shell fragments. In the literature the complications in some cases are seen after 17 years of trauma (11), and one can speculate that with increasing follow-up there can be complications. Its true, nevertheless, the results of our study gives a major contribution to the English literature with being the largest series showing no complication of renal retaining foreign bodies with in a mean 38.7 months of follow-up.

Everyone must keep in mind that all our encouraging results of non-operative management for renal injuries caused by shell fragments are taken from the database of a tertiary university hospital that harbor experienced 24-hour in-house trauma surgeons, interventional radiologists, and medical staff. So nonoperative management options may not be applicable for all medical centers. Again we must keep in our minds that careful observation and close monitoring are the essential parts of conservative managements in all renal injuries. If there is a lack of an experienced team, exploration options or referring patient to a more experienced center might be a safer alternative for both surgeon and patient. The major limitation of our study is its retrospective manner.

\section{Conclusion}

Our study shows that non-operative management of shell fragments caused renal injuries lead excellent result with low complication rate and high chance of renal preservation even in the presence of retaining renal shell fragments. It requires close hemodynamic monitoring and careful observation. Urinary diversion with nephrostomy/d-j catheter and selective arterial embolization plays a major role in complication management, and leads higher non-operative management success. However, we must keep in mind that this kind of management is safe in experienced trauma centers that have experienced staff.

\section{Declarations}

Availability of data and materials: The datasets used and analyzed during the current study are available from the corresponding author on reasonable request.

Acknowledgments: Not applicable.

Funding: No funding was received for this research.

\section{Author information}

Affiliations

Department of Urology, Gulhane Medical University, Ankara, 06010, Turkey

Department of Radiology, Gulhane Medical University, Ankara, 06010, Turkey

\section{Contributions}

MZ and BT designed the study. BT performed data collection and data analysis and drafted the manuscript. MZ, EK, and SB contributed to reviewing and editing the manuscript. SY was in charge of overall direction and planning. All authors read and approved the final manuscript.

\section{Corresponding author}

Correspondence to Murat ZOR.

\section{Ethics declarations}

\section{Ethics approval and consent to participate}

This study was approved by the Gulhane Medical Faculty ethics committee (2018-18-87). As this study was a retrospective cohort study, informed consent was not obtained.

\section{Consent for publication}

Not applicable.

\section{Competing interests}

The authors declare that they have no competing interests.

\section{References}

1. Bjurlin MA, Jeng El, Goble SM, Doherty JC, Merlotti GJ. Comparison of nonoperative management with renorrhaphy and nephrectomy in penetrating renal injuries. J Trauma. 2011;71(3):554-8.

2. Voelzke BB, McAninch JW. Renal gunshot wounds: clinical management and outcome. J Trauma. 2009 Mar;66(3):593-600.

3. Corriere JN Jr, McAndrew JD, Benson GS. Intraoperative decisionmaking in renal trauma surgery. J Trauma. 1991;31:1390-2.

4. Bergren CT, Chan FN, Bodzin JH. Intravenous pyelogram results in association with renal pathology and therapy in trauma patients. J Trauma. 1987;27:515-8. 
5. Peyser A, Khoury A, Liebergall M. Shrapnel management. J Am Acad Orthop Surg. 2006;14(10 Spec No.):S66-70.

6. Korzinek K. War injuries of the extremities. Unfallchirurg. 1993 May;96(5):242-7.

7. Moore EE, Shackford SR, Pachter HL, et al. Organ injury scaling: spleen, liver, and kidney. J Trauma. 1989;29:1664 -6.

8. Eskridge SL, Macera CA, Galarneau MR, Holbrook TL, Woodruff SI, MacGregor AJ, et al. Injuries from combat explosions in Iraq: injury type, location, and severity. Injury 2012; 43:1678-82.

9. Champion HR, Holcomb JB, Young LA. Injuries from explosions: physics, biophysics, pathology, and required research focus. J Trauma $2009 ; 66: 1468-77$.

10. Mantica G, Kruger S, Ackermann H, Spies PV, Cassim F, Keyser Z, Terrone C, van der Merwe A. Retained Bullet in the Kidney: Imaging and Conservative Management. Urology. 2018;113:e3-e4.

11. Naeem I, Masood J, Buchholz N. Percutaneous nephrolithotomy for removal of a calcified intra-renal artillery shell fragment. J R Army Med Corps. 2009;155(1):30-1.

12. Gourgiotis S, Germanos S, Dimopoulos N, Vougas V, Anastasiou T, Baratsis S. Renal injury: 5-year experience and literature review. Urol Int. 2006;77(2):97103. Review.

13. Cheng DL, Lazan D, Stone N: Conservative management of type III renal trauma. J Trauma 1994; 36: 491-4.

14. Velmahos GC, Demetriades D, Cornwell EE 3rd, Belzberg H, Murray J, Asensio J, Berne TV: Selective management of renal gunshot wounds. Br J Surg 1998; 85: 1121-4.

15. Cooper GJ, Ryan JM. Interaction of penetrating missiles with tissues: some common misapprehensions and implications for wound management. Br $\mathrm{J}$ Surg. 1990;77(6):606-10.

16. Hayda R, Harris RM, Bass CD. Blast injury research: modeling injury effects of landmines, bullets, and bombs. Clin Orthop Relat Res. 2004;(422):97-108.

17. Petersen K, Waterman P. Prophylaxis and treatment of infections associated with penetrating traumatic injury. Expert Rev Anti Infect Ther. 2011;9(1):8196.

18. Coon T, Miller M, Shirazi F, Sullivan J. Lead toxicity in a 14-year female with retained bullet fragments. Pediatrics 2006 ; $117: 227-30$.

\section{Tables}

Table 1. The patient and renal injury characteristics of all patients.

\begin{tabular}{|c|c|c|c|c|c|c|c|c|c|c|c|c|}
\hline \multirow{2}{*}{$\begin{array}{l}\text { Patient } \\
\text { No }\end{array}$} & \multirow{2}{*}{$\begin{array}{l}\text { Age } \\
\text { (years) }\end{array}$} & \multirow{2}{*}{$\begin{array}{l}\text { Site } \\
\text { of } \\
\text { injury }\end{array}$} & \multirow{2}{*}{$\begin{array}{l}\text { Location of } \\
\text { shell } \\
\text { fragment }\end{array}$} & \multirow{2}{*}{$\begin{array}{l}{ }^{*} \text { AAST } \\
\text { renal } \\
\text { injury } \\
\text { grade }\end{array}$} & \multirow{2}{*}{$\begin{array}{l}\text { Macroscopic } \\
\text { hematuria }\end{array}$} & \multirow{2}{*}{$\begin{array}{l}\text { Systolic } \\
\text { blood } \\
\text { pressure } \\
(\mathrm{mmHg})\end{array}$} & \multirow{2}{*}{$\begin{array}{l}\text { Pulse } \\
\text { rate } \\
\text { (bpm) }\end{array}$} & \multicolumn{4}{|c|}{ Blood analysis at admission } & \multirow{2}{*}{$\begin{array}{l}\text { Blood a } \\
\begin{array}{l}\text { Serum } \\
\text { hemoglı } \\
(\mathrm{gr} / \mathrm{dl})\end{array}\end{array}$} \\
\hline & & & & & & & & $\begin{array}{l}\text { Serum } \\
\text { hemoglobin } \\
(\mathrm{gr} / \mathrm{dl})\end{array}$ & $\begin{array}{l}\text { Serum } \\
\text { hematocrit } \\
(\%)\end{array}$ & $\begin{array}{l}\text { Serum } \\
\text { urea } \\
(\mathrm{mg} / \mathrm{dl})\end{array}$ & $\begin{array}{l}\text { Serum } \\
\text { creatinine } \\
(\mathrm{mg} / \mathrm{dl})\end{array}$ & \\
\hline 1 & 25 & Right & $\begin{array}{l}\text { Renal } \\
\text { parenchyma }\end{array}$ & 2 & No & $135 / 80$ & 76 & 17,4 & 51,4 & 24 & 0,68 & 16 \\
\hline 2 & 25 & Right & $\begin{array}{l}\text { Renal } \\
\text { parenchyma }\end{array}$ & 3 & Yes & $128 / 75$ & 72 & 15,7 & 43,4 & 27 & 1,02 & 12,7 \\
\hline 3 & 25 & Left & $\begin{array}{l}\text { Collecting } \\
\text { system }\end{array}$ & 3 & No & $130 / 85$ & 68 & 18,5 & 52 & 22 & 1,14 & 16 \\
\hline 4 & 26 & Right & $\begin{array}{l}\text { Renal } \\
\text { parenchyma }\end{array}$ & 3 & Yes & $126 / 70$ & 74 & 12,7 & 36,2 & 49 & 1,68 & 8,2 \\
\hline 5 & 29 & Right & $\begin{array}{l}\text { Renal } \\
\text { parenchyma }\end{array}$ & 2 & No & $115 / 72$ & 72 & 14,9 & 41,8 & 40 & 0,92 & 15,8 \\
\hline 6 & 44 & Left & $\begin{array}{l}\text { Renal } \\
\text { parenchyma }\end{array}$ & 1 & No & $125 / 75$ & 75 & 14,4 & 41,1 & 28 & 1,14 & 14,2 \\
\hline 7 & 25 & Right & $\begin{array}{l}\text { Renal } \\
\text { parenchyma }\end{array}$ & 3 & No & $130 / 80$ & 70 & 16,8 & 48,2 & 32 & 1,02 & 16,2 \\
\hline 8 & 24 & Right & $\begin{array}{l}\text { Renal } \\
\text { parenchyma+ } \\
\text { collecting } \\
\text { system }\end{array}$ & 4 & Yes & $98 / 64$ & 88 & 9,3 & 26,3 & 71 & 1,62 & 10,3 \\
\hline
\end{tabular}

*American Association for the Surgery of Trauma (AAST) organ injury severity score for kidney

\section{Figures}




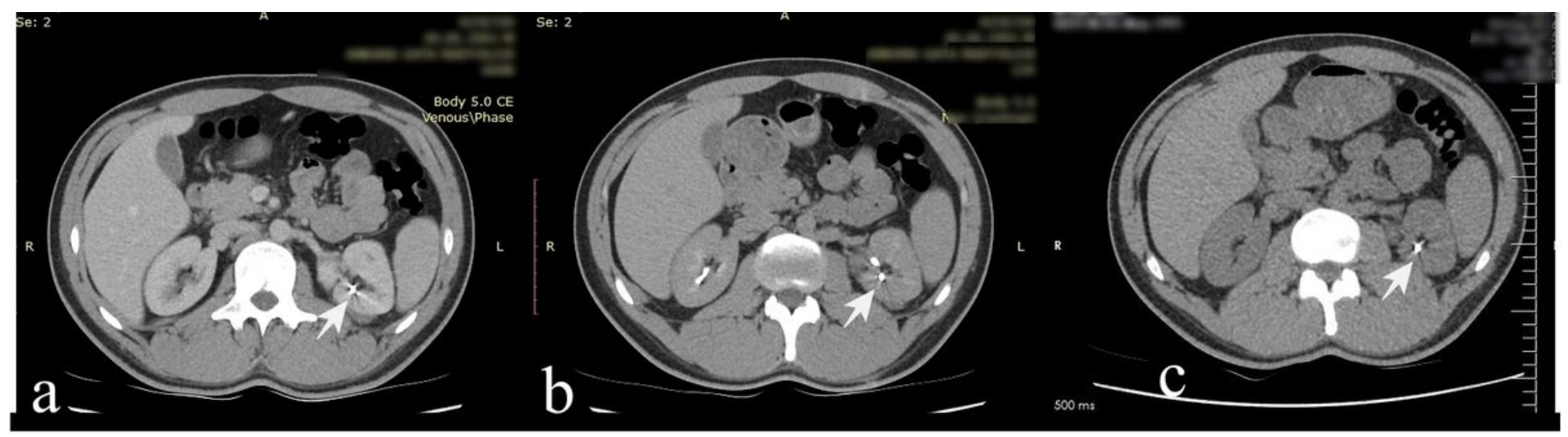

Figure 1

An AAST grade 3 renal shrapnel injury with a retaining metallic shrapnel in the left kidney of a 25 year-old male patient. Figures $1 \mathrm{a}$ and $1 \mathrm{~b}$ shows the venous phase and delayed phase tomography images of the injury, and $1 \mathrm{c}$ the control (1th month) non-contrast enhanced images. Arrows show the retaining shell fragments. Note that there is no urinary extravasation, but parenchymal laceration greater than $1 \mathrm{~cm}$.

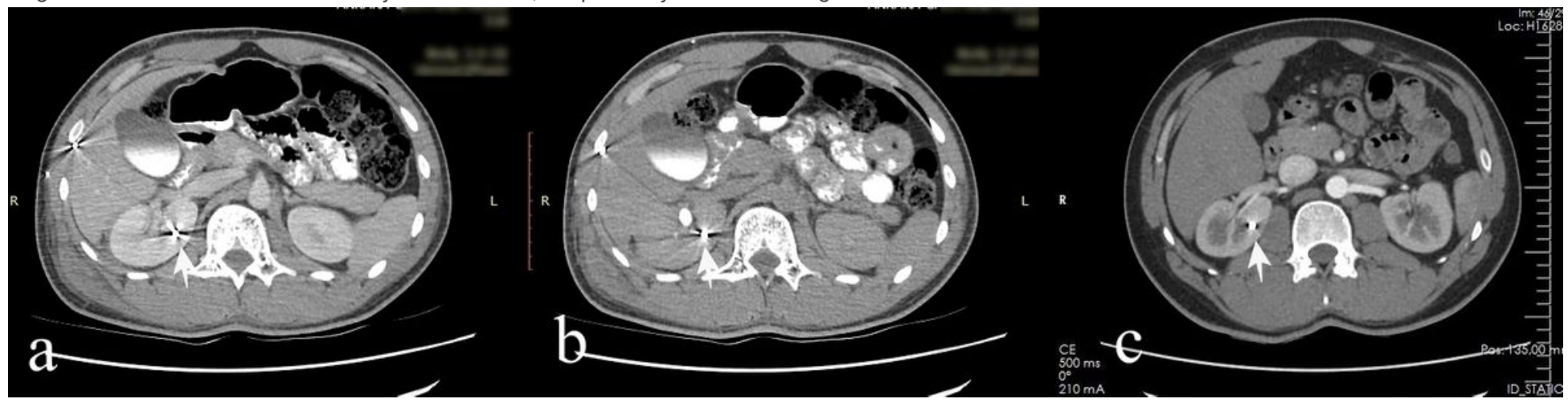

Figure 2

An AAST grade 3 renal shrapnel injury with a retaining metallic shrapnel in the right kidney of a 25 year-old male patient. Figures $1 \mathrm{a}$ and $1 \mathrm{~b}$ shows the venous phase and delayed phase tomography images of the injury, and 1c the control (1th month) venous phase images. Arrows show the retaining shell fragments. Again note the absence of urinary extravasation, but parenchymal laceration greater than $1 \mathrm{~cm}$.

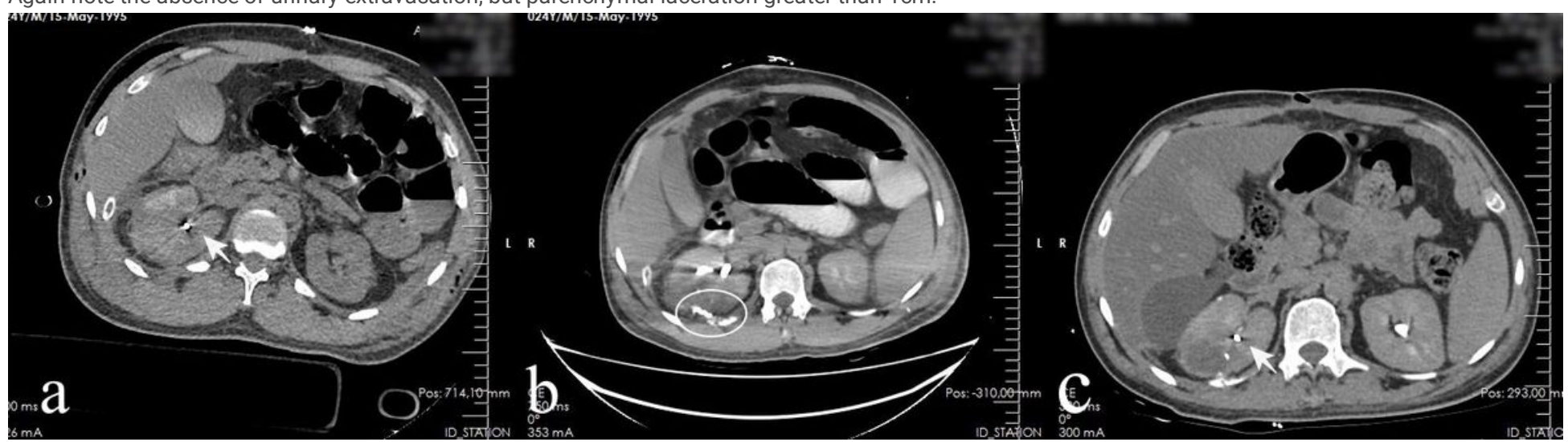

Figure 3

An AAST grade 4 renal shrapnel injury with a retaining metallic shrapnel in the right kidney of a 24 year-old male patient. Figures $1 \mathrm{a}$ and $1 \mathrm{~b}$ shows the venous phase and delayed phase tomography images of the injury, and 1c the control (1th week) delayed phase images. Arrows show the retaining shell fragments. The circle shows the urinary extravasation (fig 1b), that was resolved in control delayed phase images (figure 1c). 